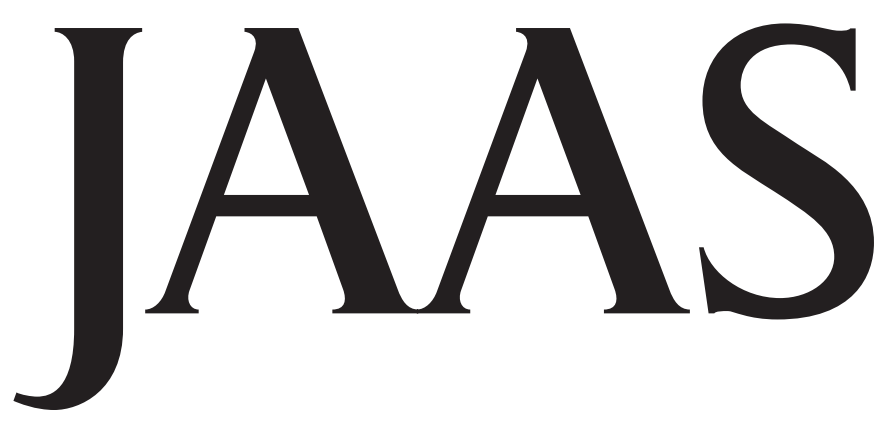

Journal of Analytical Atomic Spectrometry

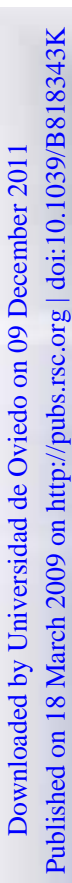

Molchan et al.

The concept of plasma cleaning in glow discharge spectrometry

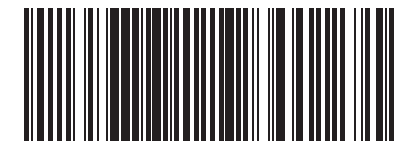

0267-9477(2009)24:6;1-O 


\title{
The concept of plasma cleaning in glow discharge spectrometry
}

\author{
I. S. Molchan, ${ }^{* a}$ G. E. Thompson, ${ }^{a}$ P. Skeldon, ${ }^{a}$ N. Trigoulet,${ }^{a}$ P. Chapon, ${ }^{b}$ A. Tempez, ${ }^{b}$ J. Malherbe, ${ }^{b}$ \\ L. Lobo Revilla,${ }^{c}$ N. Bordel, ${ }^{d}$ Ph. Belenguer, ${ }^{e}$ T. Nelis, ${ }^{e}$ A. Zahri, ${ }^{e}$ L. Therese, ${ }^{f}$ Ph. Guillot,${ }^{f}$ M. Ganciu, ${ }^{g h}$ \\ J. Michler ${ }^{i}$ and M. Hohl ${ }^{i}$
}

\author{
Received 16th October 2008, Accepted 6th March 2009 \\ First published as an Advance Article on the web 18th March 2009 \\ DOI: 10.1039/b818343k
}

\begin{abstract}
A plasma cleaning procedure to improve elemental depth profiling of shallow layered materials by glow discharge spectrometry is proposed. The procedure is based on two approaches applied prior to depth profiling, either individually or sequentially. The first approach employs a plasma generated at low power, i.e. a "soft" plasma, for removal of contaminants adsorbed on the surface of the target material. In the second approach, sacrificial material is sputtered under normal conditions, e.g. those used for depth profiling, to clean the inner surface of the anode of the glow discharge source. It is demonstrated that plasma cleaning in glow discharge optical emission spectrometry and glow discharge time-of-flight mass spectrometry improves significantly the spectrum of the target material, particularly at the commencement of sputtering due to stabilisation of the plasma as a result of removal of contaminants. Furthermore, modelling and validation studies confirmed that the soft plasma cleaning does not sputter the target material.
\end{abstract}

\section{Introduction}

Glow discharge optical emission spectrometry (GD OES) and glow discharge mass spectrometry (GD MS) are well known techniques for elemental analysis of solid materials. GD OES is used extensively for ultra-fast surface and depth profile analyses of coatings and layered materials. Furthermore, conductive and non-conductive materials may be analysed employing RF discharge excitation. ${ }^{1}$ GD MS is mainly dedicated to sensitive bulk analysis of conductive metals, allowing detection of trace elements down to sub-ppb levels. ${ }^{2}$ Interestingly, recent results with a prototype RF glow discharge time-of-flight mass spectrometry (RF GD TOFMS) have shown promise for elemental and molecular depth profiling of materials. ${ }^{3,4}$

The GD technique relies on the sputtering of a relatively large area of a target material by a plasma, followed by excitation/ ionisation of the sputtered species and, finally, the detection of the emission/ionic signals. In most configurations, the specimen seals the GD chamber and acts as the powered electrode of the

${ }^{a}$ Corrosion and Protection Centre, School of Materials, The University of Manchester, PO Box 88 Manchester, M60 1QD, UK. E-mail: igor. molchan@manchester.ac.uk; Fax: +44 (0)161 3064865; Tel: $\quad+44$ (0) 1613064828

${ }^{b}$ HORIBA Jobin Yvon, Longjumeau, 91160, France

'Department of Physical and Analytical Chemistry, Faculty of Chemistry, University of Oviedo, 33006 Oviedo, Spain

${ }^{d}$ Department of Physics, Faculty of Science, University of Oviedo, 33007 Oviedo, Spain

${ }^{e}$ Laplace, UMR 5213, Université Paul Sabatier, 31062 Toulouse, France ${ }^{f}$ DPHE, ERT 2000, Université J.F Champollion, 81012 Albi, France

${ }^{g}$ National Institute of Lasers, Plasma and Radiation Physics, Bucharest. Magurele, 077125, Romania

${ }^{h}$ Laboratoire de Physique des Gaz et des Plasmas, UMR CNRS-UPS 8578 , Université Paris-Sud, 91405 Orsay, France

${ }^{i}$ EMPA, Swiss Federal Laboratories for Materials Testing and Research, Laboratory for Mechanics of Materials and Nanostructures, Feuerwerkerstr. 39, 3602 Thun, Switzerland glow. The simple geometry, where the source, exposed to ambient atmosphere, is switched to medium vacuum prior to plasma initiation, has raised concern about the capability of the technique for precise surface and near-surface analyses. However, results have proved that, in some cases, GDS techniques can provide sub-nanometre depth resolution and monitoring of shallow elemental depth distributions. ${ }^{5}$

In order to resolve the structure of very near-surface layers, it is crucial to provide conditions for stable plasma generation at the beginning of sputtering. This can be realised through minimising contaminants from the carrier gas and from the specimen and anode surfaces. ${ }^{6}$ It is well known that the carrier gas purity is one of the most critical parameters for reliable GD analysis; but even if the partial pressure of contaminants in the gas is very low, a monolayer of impurities is formed within a very short time (at argon pressures of 10 mbar, a monolayer is formed within $500 \mathrm{~ns}$ assuming a sticking probability of 1 and using kinetic theory of gases with Maxwellian velocity distribution and perfect gas law).

Consequently, the main source of contamination arises from species adsorbed on the walls of the GD source, namely the inner surface of the anode and the specimen surface. Such contamination leads to a poor start of the discharge (signal spikes) influencing the quality of the measurements. The presence of organics, adsorbed water and hydrogen also strongly influences the emission yields of some elements in OES, requiring corrections. $^{7}$ In MS, additional contamination-related peaks make interpretation difficult.

Consequently, specimens should be carefully manipulated and cleaned, ${ }^{\mathbf{8}}$ which is not always possible in practice. On the other hand, the source walls can be cleaned by sputtering of a sacrificial specimen under standard depth profiling conditions prior to the analysis of the specimen. Sputtering of the sacrificial specimen results in coverage of the anode surface with a thin layer of sacrificial material. The use of monocrystalline silicon as the sacrificial specimen may be effective. ${ }^{9}$ However, careful selection 
of the sacrificial specimen is important to avoid distortion of the depth profile, since the sacrificial material may be removed from the inner walls of the anode during depth profiling. This approach is an excellent alternative to cleaning the discharge chamber using solvents and other chemicals that, generally, are not completely removed from the surface and often leave surface residues. Furthermore, most of the commonly used solvents, e.g. methanol, toluene, dimethylformamide, etc. are hazardous.

A simple and complementary approach to enable cleaning of both the specimen surface and the inner walls of the anode in one process is proposed here. The approach consists of the generation of a low energy plasma once the specimen is mounted onto the GD source and prior to GD depth profiling. This low energy, or so-called "soft", plasma is generated using a discharge at reduced power. The challenge for this soft cleaning is obviously to avoid sputtering of the specimen and modification of the composition during the cleaning process.

\section{Modelling of sputtering}

Generally, the sputtering rate depends on the energy, mass, and angle of incidence of the ions, but not on their charge because the ions are neutralised at the surface. ${ }^{10}$ The sputtering yields are identical for ions or neutrals. Sputtering is of importance for surface science and materials research; many studies contain yield measurements, as reviewed by Smentkowski. ${ }^{11}$ The sputtering rate can be experimentally measured, but analytical theories are also available. The analytical theory of sputtering due to nuclear interaction was developed by Sigmund, ${ }^{12}$ who considered the incident particle to make binary collisions with the target atoms. During these collisions, some target atoms receive sufficient energy to be sputtered. The hypothesis of binary collisions implies a validity range to this theory, since it is only applicable if the incident particles have sufficiently high energy or mass. In order to consider the energies close to the sputtering threshold and also light particles, the original theory has been modified accordingly, as discussed by Pedoussat and Macé. ${ }^{13}$ One of the most recent theories, formulated by Yamamura, ${ }^{14}$ is based on data for different sputtered materials. Generally, the agreement between the semi-empirical formulae of Yamamura and the measurements is good, even at the threshold energy.

In this study, GD OES and GD TOFMS data, demonstrating the cleaning efficiency of the soft plasma procedure, are discussed. The experimental data are complemented by theoretical calculations of ion energies supporting the experimental observation of the absence of sputtering. The ion energy distribution functions have been calculated through a Monte Carlo model for ions, where the electric field and ion source terms, determined from a hybrid fluid Monte Carlo model of the discharge, are used as input parameters.

\section{Experimental}

\section{Specimen preparation}

Electropolished aluminium, electropolished aluminium supporting an anodic alumina film with a buried chromium delta layer, and platinum layers on monocrystalline silicon wafer and on a rigid polymer, were employed. A monocrystalline silicon wafer was also used as a sacrificial material.
A superpure aluminium (99.99 wt $\%$ Al, impurities: Fe, 8 ppm; $\mathrm{Si}, 8 \mathrm{ppm}$; $\mathrm{Cu}, 50 \mathrm{ppm}$ ) sheet of $0.3 \mathrm{~mm}$ thickness was cut to provide specimens of dimensions of $35 \times 70 \mathrm{~mm}$. Specimens were individually electropolished in a $20 / 80 \mathrm{vol} \%$ perchloric acid/ ethanol solution at a constant voltage of $20 \mathrm{~V}$ for $10 \mathrm{~min}$ at temperatures between $5-10{ }^{\circ} \mathrm{C}$; they were then rinsed thoroughly with ethanol and deionised water, and finally dried in a cool air stream. For generation of an anodic film with a chromium delta layer, the electropolished aluminium specimens were treated in $20 \mathrm{~g} \mathrm{l}^{-1} \mathrm{CrO}_{3}-35 \mathrm{ml} \mathrm{l}^{-1} \mathrm{H}_{3} \mathrm{PO}_{4}$ at $90{ }^{\circ} \mathrm{C}$ for $5 \mathrm{~min}$. After rinsing in deionised water and drying in a hot air stream, they were anodised in $0.1 \mathrm{M}$ ammonium pentaborate at $5 \mathrm{~mA} \mathrm{~cm} \mathrm{~cm}^{-2}$ to $300 \mathrm{~V}$, rinsed and dried in cold air stream. For the selected conditions, an anodic alumina film of $360 \mathrm{~nm}$ thickness, with an approximately $4 \mathrm{~nm}$ thick chromium-enriched delta layer located $50 \mathrm{~nm}$ from the surface of the anodic alumina, is generated. ${ }^{15}$

The monocrystalline silicon wafer and the rigid polymer (polyester) were coated by deposition of a $20 \mathrm{~nm}$ thick platinum layer, using a table top magnetron sputtering device operating in high power pulsed mode developed in a collaboration between National Institute of Lasers, Plasma and Radiation Physics, Laboratoire de Physique des Gaz et des Plasmas and HORIBA Jobin Yvon. This technique allows deposition on complex surfaces while maintaining a very compact coating. ${ }^{16}$

\section{GD OES characterisation}

For GD OES analysis, a GD-Profiler 2 (Horiba Jobin Yvon, France) operating in radio frequency at $13.56 \mathrm{MHz}$ was employed. A $4 \mathrm{~mm}$ diameter copper anode and argon gas were used. The emission responses from the excited sputtered elements were detected with a polychromator of focal length of $500 \mathrm{~mm}$. The emission lines used were $396.15 \mathrm{~nm}$ for aluminium, $249.67 \mathrm{~nm}$ for boron, $156.14 \mathrm{~nm}$ for carbon, $425.43 \mathrm{~nm}$ for chromium, $324.75 \mathrm{~nm}$ for copper, $121.56 \mathrm{~nm}$ for hydrogen, $371.99 \mathrm{~nm}$ for iron, $130.21 \mathrm{~nm}$ for oxygen, $127.28 \mathrm{~nm}$ for phosphorus and $288.15 \mathrm{~nm}$ for silicon. For plasma cleaning, the power was varied from 2 to $5 \mathrm{~W}$ with an argon pressure in the range 200 to $750 \mathrm{~Pa}$. Subsequent elemental depth profiling was carried out at $750 \mathrm{~Pa}$ and $35 \mathrm{~W}$.

\section{GD TOFMS characterisation}

A description of the GD TOFMS instrument is given elsewhere. ${ }^{17}$ The instrument, shown schematically in Fig. 1, comprises a modified Grimm GD source coupled to a very fast orthogonal TOFMS (Tofwerk, Switzerland). The system offers the unique advantage of quasi-simultaneous detection of elemental and molecular ions of all masses typically below $1000 \mathrm{Da} .{ }^{4}$ Unlike GD OES, GD TOFMS also provides direct information about positive molecular ions containing $\mathrm{H}, \mathrm{C}, \mathrm{N}$, and $\mathrm{O}$ that are related to the presence of surface and gas contaminants.

The reflector-based TOFMS has a mass resolving power of 3000 at mass 209. For the cleaning of the discharge chamber, an argon pressure and power of $650 \mathrm{~Pa}$ and $2 \mathrm{~W}$, respectively, applied for $2 \mathrm{~min}$ to the anodised aluminium specimens, were selected. The subsequent depth profiling was undertaken at $650 \mathrm{~Pa}$ and $40 \mathrm{~W}$. This procedure is similar to that employed in the GD OES experiments. 


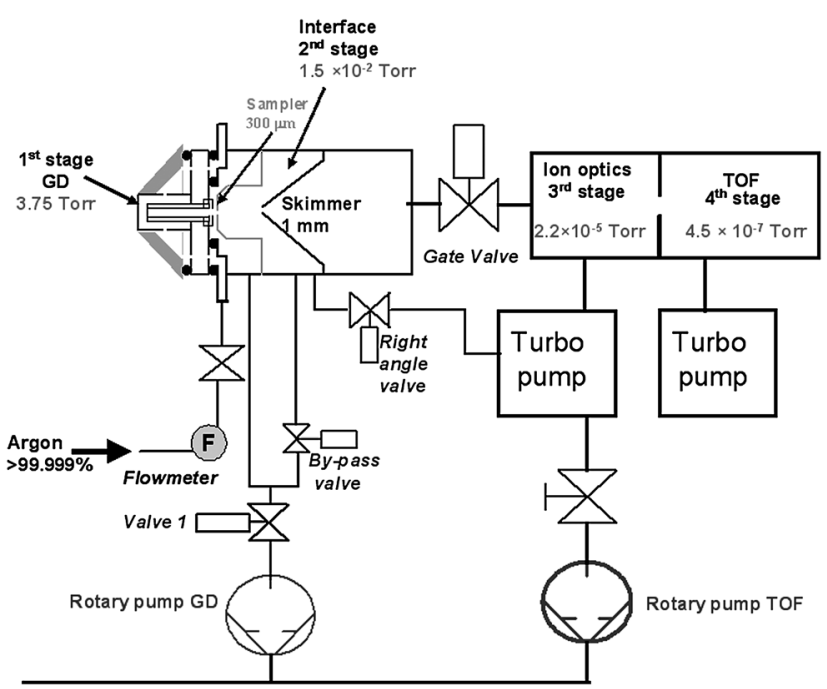

Fig. 1 Schematic diagram of the GD TOFMS instrument.

\section{Simulation}

Hybrid model for the discharge. A 2D cylindrical hybrid (FluidMonte Carlo), self-consistent model of the discharge has been employed. The model has been previously used for dc and RF glow discharges. ${ }^{18}$ For the model, fluid equations are used to describe ions and electrons that contribute to the space charge; the equations are solved self-consistently with Poisson's equation for the electric field. The secondary electrons responsible for ionisation are treated by a Monte Carlo approach. The densities of charged particles, the ionisation source term and the electric field as a function of space and time result from the model. These results are then used as input parameters for the Monte Carlo model for the ions.

Monte Carlo model for the ions. The model describes ion transport in the sheath. Ions are created according to the ionisation source term calculated from the $2 \mathrm{D}$ hybrid model of the discharge. The transport of the ions in the sheath is related to the electric field distribution and collisions. Collision cross-section data are required for the model, with elastic collisions considered. For energies below a few hundred eV (the energy range for sputtering), inelastic collisions are negligible. Cross sections for elastic collisions are available from Phelps, ${ }^{19}$ where the differential and angular integrated cross sections are calculated for elastic collisions from potential energy curves.

It is considered that the cell geometry is typical of a Grimm type source, with a $4 \mathrm{~mm}$ diameter cylindrical electrode, $10 \mathrm{~mm}$ length and separated from the RF powered electrode by a $0.15 \mathrm{~mm}$ thick dielectric. The physical characteristics of the modelled reactor are $20 \mathrm{~mm}$ axial length and $12 \mathrm{~mm}$ radial width. The RF voltage is applied through a capacitor. The gas considered is argon, with an applied voltage of $V=V_{\mathrm{rf}} \cos (t)$, and frequency of $13.56 \mathrm{MHz}$. As the RF voltage is applied through a capacitor, the typical dc bias voltage for this discharge is calculated self-consistently. The input pressure and RF voltage used in the model are similar to the average experimental conditions, namely $400 \mathrm{~Pa}$ and $-170 \mathrm{~V}$ respectively.

\section{Results and discussion \\ GD OES}

Fig. 2 shows GD OES elemental depth profiles of the electropolished aluminium in the absence of plasma cleaning. The shoulder in the aluminium profile and increased oxygen intensity at the start of sputtering indicate the presence of air-formed oxide film of about $2 \mathrm{~nm}$ thickness on the surface of aluminium. The subsequent steep increase of the aluminium intensity, followed by a plateau region, and the decreasing oxygen intensity reveal sputtering of aluminium. A relatively thin, about $2 \mathrm{~nm}$ thick, copper-enriched layer is located just beneath the oxide film. This results from preferential anodic oxidation of aluminium in the presence of a residual alumina film during electropolishing. ${ }^{20} \mathrm{~A}$ high carbon surge is evident at the commencement of sputtering that nearly coincides with an increase in the hydrogen intensity. Both hydrogen and carbon signals originate from contamination of the specimen and internal anode surfaces caused by hydrocarbons, free carbon, water $e t c$. adsorbed on the surface. In addition, the total light, Fi, recorded by a spectral broad band detector, shows a surge similar to the carbon profile at the commencement of sputtering. As the broad band emission of the discharge is sensitive to molecular band emission, it indicates instability of the plasma, possibly resulting from hydrocarbon contaminants. Scrutiny of the initial region of the profile shows similar surges for most of the detected elements, including trace elements with responses at background levels, e.g. copper, phosphorus, iron, chromium, etc. These surges are thought to be linked to instability of the plasma at the commencement of sputtering (see Fi profile), with a possible contribution from interfering molecular band emission. ${ }^{21}$ If no cleaning procedure is undertaken, the high initial carbon surge usually causes instability of the plasma, evident as the surge of Fi; however, currently, the link between surges of carbon and Fi is not well understood.

Plasma treatment at $3 \mathrm{~W}$ and $750 \mathrm{~Pa}$ for 1 min leads to a significant reduction, by approximately 10 times, of the carbon signal and to a slight decrease in the hydrogen response at the commencement of sputtering (Fig. 3). Furthermore, the initial

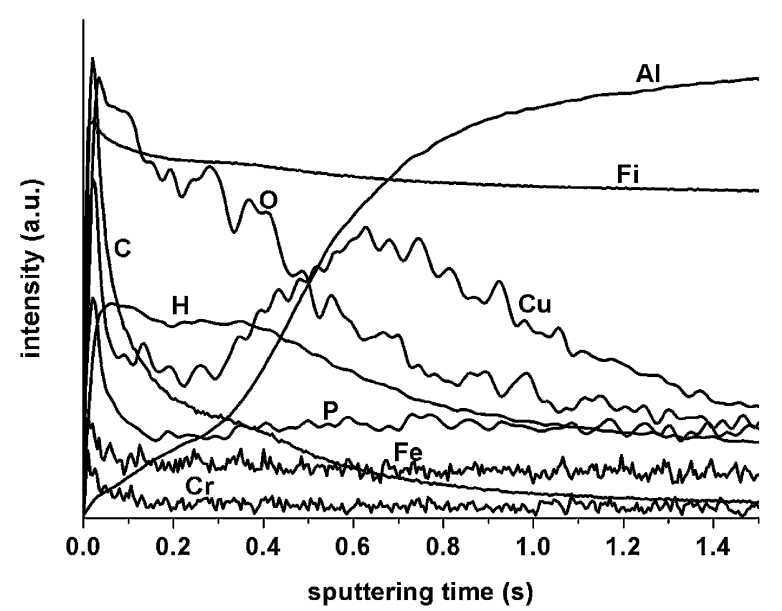

Fig. 2 GD OES depth profile of the electropolished aluminium obtained at $750 \mathrm{~Pa}$ and $35 \mathrm{~W}$ (no plasma cleaning). 


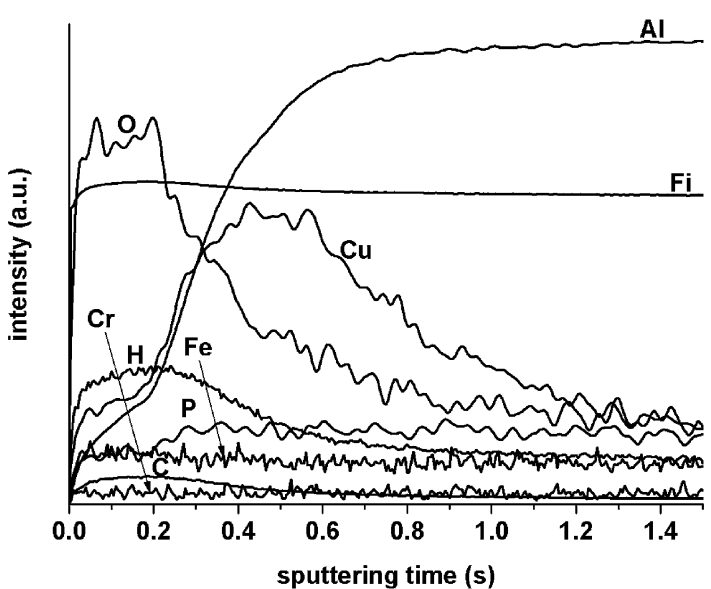

Fig. 3 GD OES depth profile of the electropolished aluminium obtained at $750 \mathrm{~Pa}$ and $35 \mathrm{~W}$ after application of plasma cleaning. Plasma cleaning conditions were pressure $750 \mathrm{~Pa}$, power $3 \mathrm{~W}$, duration $1 \mathrm{~min}$.

surge in the total plasma response (Fi) is absent. However, some initial slight plasma instabilities, following the behaviour of the carbon profile, remain evident. The initial surges in the signals of trace elements, e.g. iron, chromium, copper, decrease significantly or are absent. During the plasma cleaning process (Fig. 4), the responses from oxygen, carbon and aluminium are slightly higher than their background levels, indicating possible sputtering of the specimen material. However, the absence of significant changes in the fine features in the spectra of Fig. 2 and 3 , e.g. shape of the aluminium, oxygen and copper profiles associated with the native oxide and copper-rich regions, confirms that material loss, if any, is negligible in the present case. Even gentler cleaning, with reduced signal intensities during cleaning, can be achieved by pulsing the RF generator, but a longer cleaning time up to 15 minutes should be used.

The use of pre-cleaning by sacrificial monocrystalline silicon prior to soft plasma cleaning was also examined; silicon was employed, since it is not of interest in the specimens examined here. Pre-sputtering of a silicon wafer was carried out under

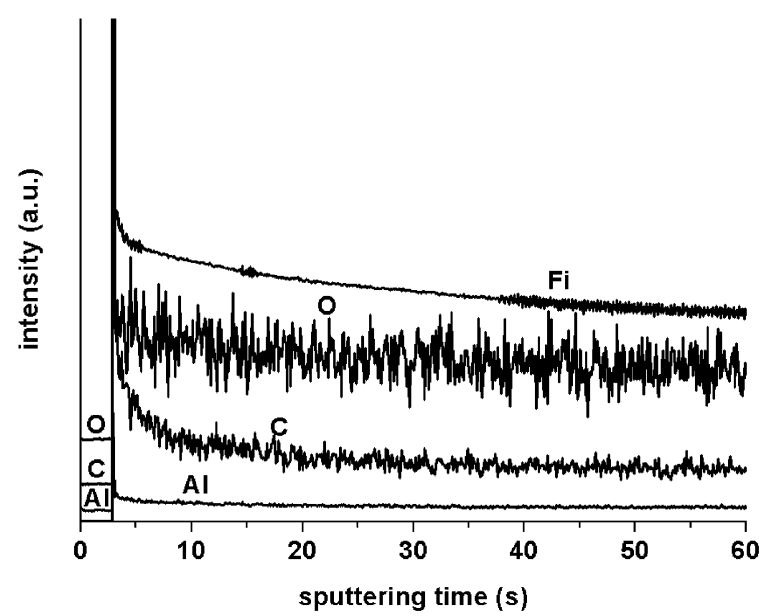

Fig. 4 GD OES depth profile obtained during plasma cleaning of the electropolished aluminium at $750 \mathrm{~Pa}$ and $3 \mathrm{~W}$; the first $3 \mathrm{~s}$ before cleaning in profile show background levels of the recorded elements.

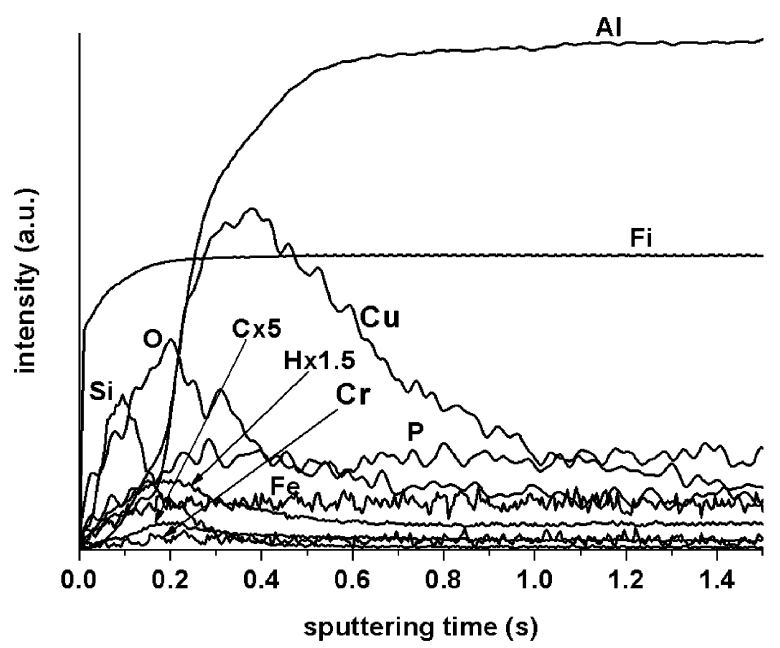

Fig. 5 GD OES depth profile of the electropolished aluminium obtained at $750 \mathrm{~Pa}$ and $35 \mathrm{~W}$ after sputtering of silicon wafer for $1 \mathrm{~min}$, followed by cleaning of specimen at $750 \mathrm{~Pa}$ and $3 \mathrm{~W}$ for $1 \mathrm{~min}$.

conditions of sputtering (750 Pa, $35 \mathrm{~W}$ ) for $1 \mathrm{~min}$, followed by rapid replacement of the wafer by the specimen to minimise recontamination of the anode walls, and plasma cleaning under the previously described conditions. A further 10-fold reduction of the carbon intensity was achieved. In addition, no surges at the beginning of sputtering for the total plasma and for the trace elements profiles are evident (Fig. 5). Some silicon is reintroduced in the discharge atmosphere and is detected during the first several tenths of a second of sputtering; however, this does not influence the profiles of the other elements, and can be ignored in the profile.

The contribution of pre-sputtering of the sacrificial specimen to cleaning is achieved in two ways. First, during sputtering of the sacrificial monocrystalline silicon at relatively high power and pressure, contaminants from the inner anode surface are effectively removed by desorption through contact with the plasma. Second, a very thin silicon layer (silicon has a low sputtering rate) is deposited on the anode walls and masks/seals the remaining, underlying contaminants during further depth profiling. The soft plasma cleaning treatment employed after pre-sputtering of silicon, but prior to elemental depth profiling, preferentially removes the contaminants from the specimen surface rather than the silicon coating on the anode. The procedure, thus, ensures a strongly reduced initial carbon level and, importantly, enhanced initial plasma stability.

The parameters for plasma cleaning, e.g. pressure, power, pulse mode settings, need to be adjusted individually for specific target materials. For instance, a power of $5 \mathrm{~W}$ and pressure of $400 \mathrm{~Pa}$ are effective for electropolished aluminium specimens, but the use of such conditions for cleaning electropolished aluminium supporting an anodic oxide film removes material of interest. Thus, Fig. 6 compares profiles of the outer region of the anodic film on aluminium, with a chromium delta layer buried $50 \mathrm{~nm}$ from the anodic film surface. ${ }^{15}$ The high carbon surge is evident at the initiation of the plasma for the non-cleaned specimen (Fig 6(a)). It is reduced significantly after application of cleaning at $400 \mathrm{~Pa}$ and $2 \mathrm{~W}$ for $1 \mathrm{~min}$. Scrutiny of the profiles in Fig. 6(a) and (b) reveals that the position of the chromium peak is 

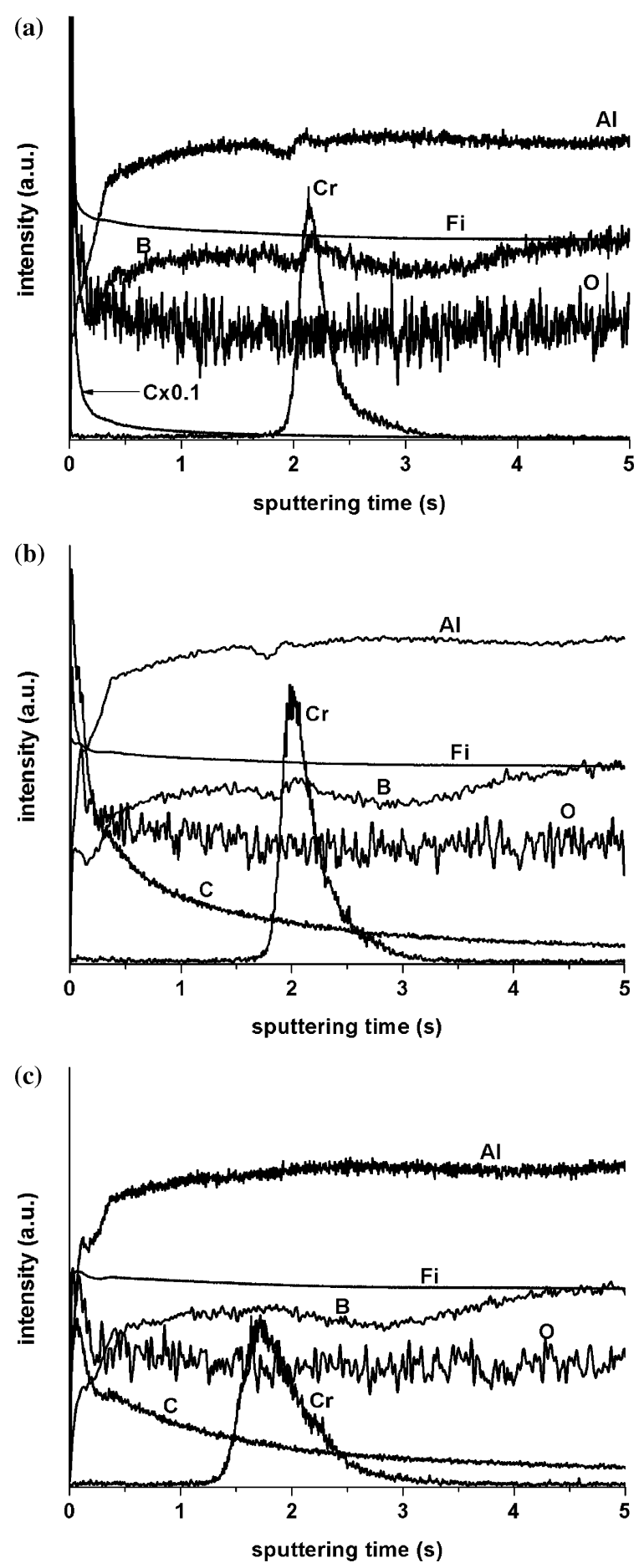

Fig. 6 GD OES depth profiles of the anodic film with buried chromium delta layer grown on aluminium obtained (a) without cleaning and with cleaning at (b) $400 \mathrm{~Pa}, 1 \mathrm{~min}, 2 \mathrm{~W}$ and (c) $400 \mathrm{~Pa} 1 \mathrm{~min}, 5 \mathrm{~W}$.

shifted to the left by approximately $0.1 \mathrm{~s}$ after cleaning that can be associated with removal of contaminants. Furthermore, the delta layer approaches the surface more closely, with its intensity reduced, when a power of $5 \mathrm{~W}$ and an argon pressure of $400 \mathrm{~Pa}$ are used for cleaning. It is clear that most materials, for example those based on aluminium, aluminium oxide, tantalum, steel etc., have different sputtering rates and, consequently, conditions applicable to one material without damage may cause damage of other materials. Ideally, by reduction of power, conditions appropriate for most materials can be determined. However, in practice, limitations on the lower achievable value of power are applied by instrument features and the compromise between the duration and efficiency of cleaning should be taken into account.

Plasma cleaning of platinum layers deposited on monocrystalline silicon and on a rigid polymer was performed at $300 \mathrm{~Pa}$ and $5 \mathrm{~W}$ in the pulsed mode ( $1 \mathrm{kHz}, 0.25$ duty cycle). When a fast acquisition at $0.001 \mathrm{~s} \mathrm{pt}^{-1}$ is used, spikes of signals from $\mathrm{CH}$, corresponding to contaminants, are evident. The specimen remains clearly undamaged after cleaning (Fig. 7).

\section{Plasma cleaning by GD TOFMS}

Fig. 8 displays the $\mathrm{CH}_{3}{ }^{+}$profile obtained from analyses of anodised aluminium with and without cleaning; no surge at the start of the plasma is visible upon cleaning. The shape of both profiles is the same but the $\mathrm{CH}_{3}{ }^{+}$profile stabilises to a lower background level when plasma cleaning is applied. Thus, plasma cleaning effectively removes adventitious surface carbon and ensures cleaner conditions from the commencement of the depth profile
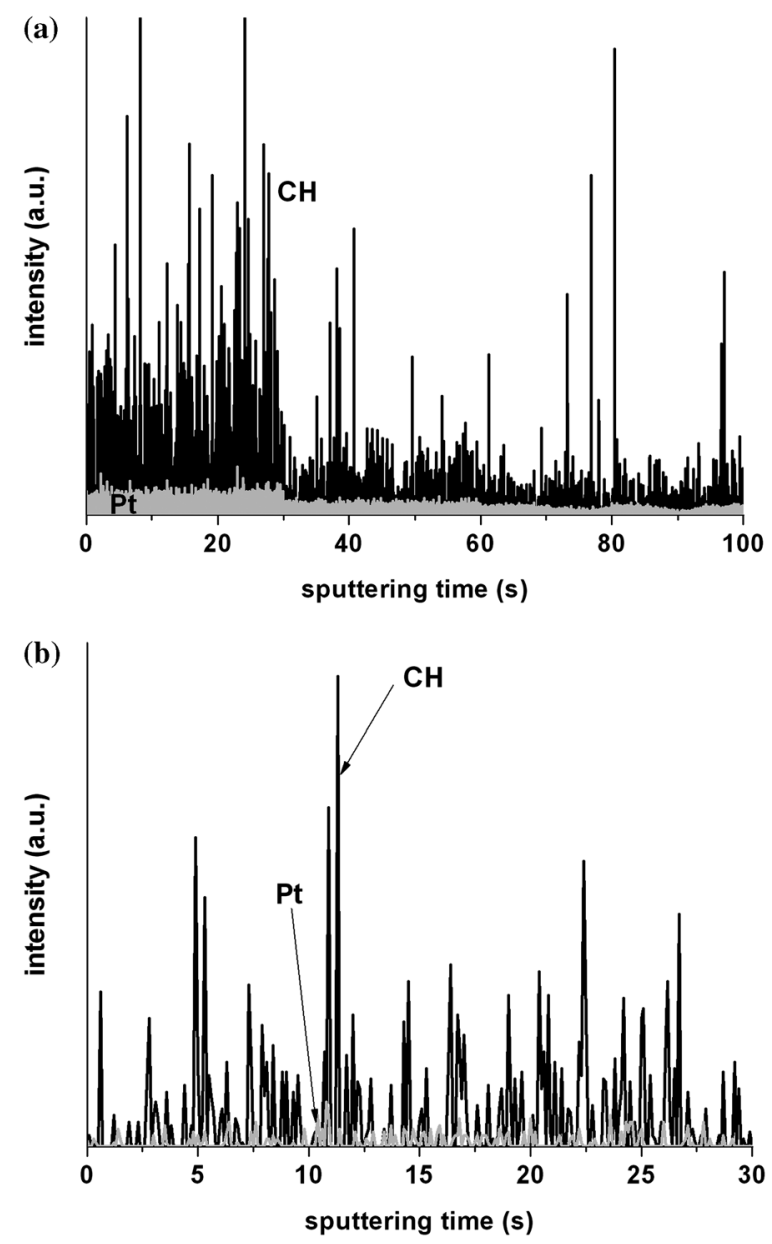

Fig. 7 Emission signals from $\mathrm{Pt}$ and $\mathrm{CH}$ corresponding to contaminant as a function of time from a $\mathrm{Pt}$ thin film on (a) $\mathrm{Si}$ and (b) polymer under a cleaning RF plasma at $300 \mathrm{~Pa}$, pulsed mode, $1 \mathrm{kHz}, 0.25$ duty cycle: $\mathrm{Pt}$ - grey, $\mathrm{CH}$ - black. 


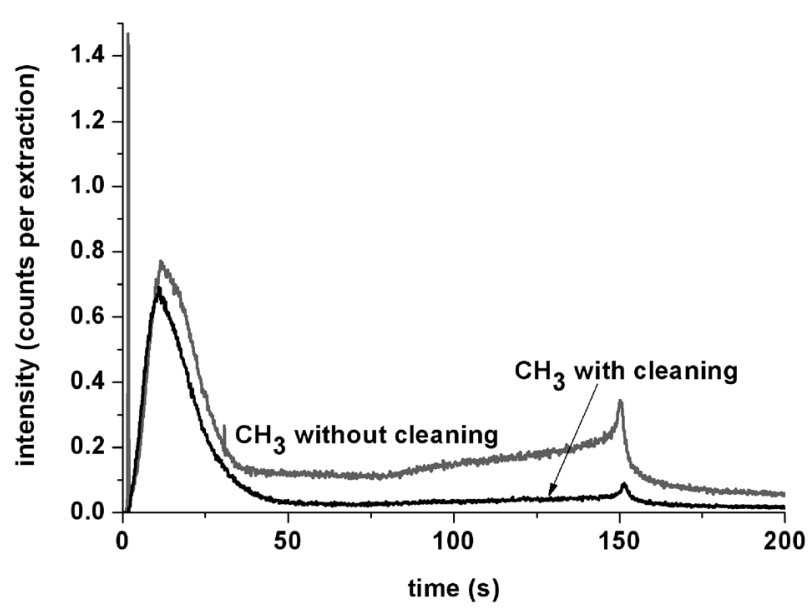

Fig. 8 Comparison of GD TOFMS $\mathrm{CH}_{3}{ }^{+}$depth profiles of anodised aluminium sputtered at $650 \mathrm{~Pa}$ and $40 \mathrm{~W}$ with and without cleaning. The plasma cleaning conditions were $650 \mathrm{~Pa}$ Ar pressure and $2 \mathrm{~W}$ RF power applied for $2 \mathrm{~min}$.
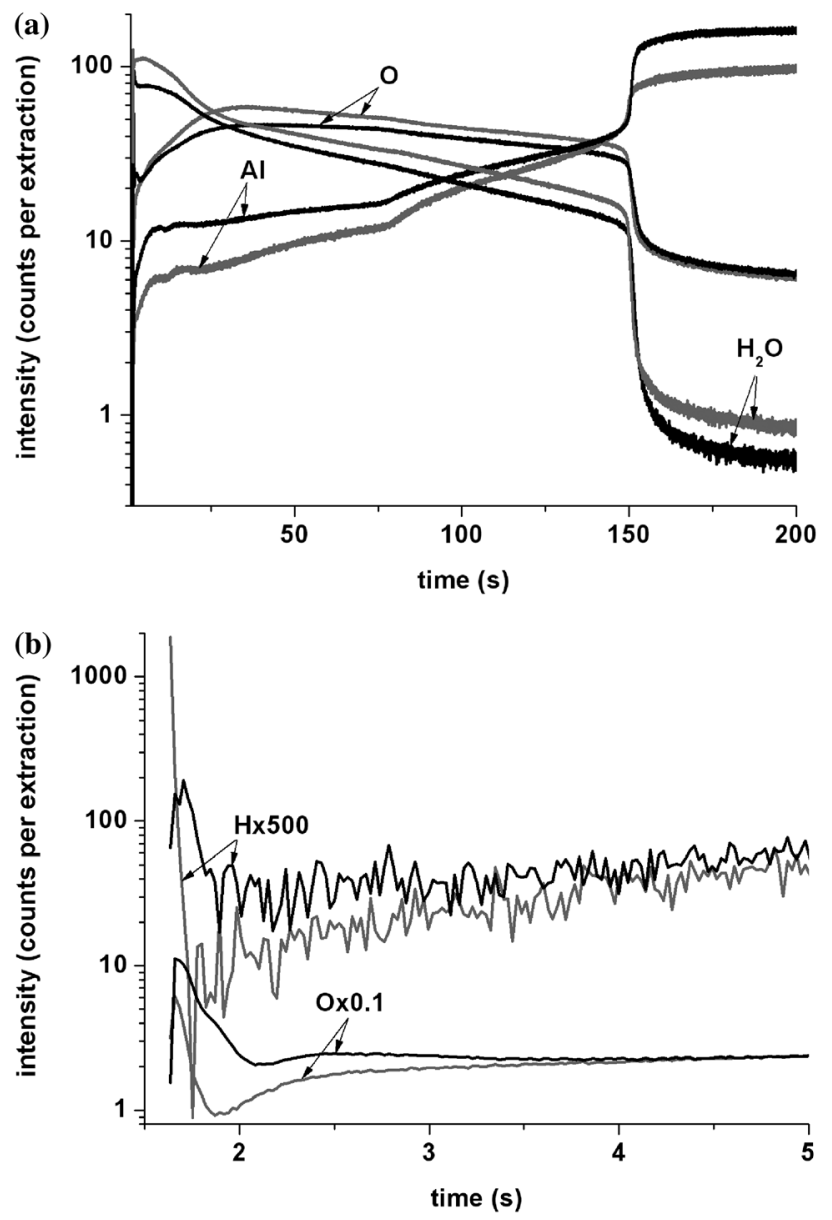

Fig. 9 Comparison of GD TOFMS depth profiles of anodised aluminium sputtered at $650 \mathrm{~Pa}$ and $40 \mathrm{~W}$ with (black lines) and without (grey lines) cleaning: (a) general view of $\mathrm{O}^{+}, \mathrm{H}_{2} \mathrm{O}^{+}$, and $\mathrm{Al}$ profiles; (b) $\mathrm{H}^{+}$ and $\mathrm{O}^{+}$profiles for the first $5 \mathrm{~s}$ of sputtering. The plasma cleaning conditions were $650 \mathrm{~Pa}$ Ar pressure and $2 \mathrm{~W}$ RF power applied for $2 \mathrm{~min}$. analysis. Fig. 9(a) shows the ${ }^{16} \mathrm{O}^{+}, \mathrm{H}_{2}{ }^{16} \mathrm{O}^{+}$and ${ }^{27} \mathrm{Al}^{+}$profiles obtained with and without cleaning. The water $\mathrm{H}_{2}{ }^{16} \mathrm{O}^{+}$signal is reduced across the entire profile when plasma cleaning is applied.

The reduction is more important in the first tens of nanometres of the oxide layer ( $40 \%$ reduction upon cleaning). Plasma cleaning not only removes adsorbed water from the exposed sample surface (initial high reduction) but also from the inner walls of the anode. The ${ }^{27} \mathrm{Al}^{+}$signal is higher across the entire profile when plasma cleaning is applied. This could be linked to reduced $\mathrm{H}_{2} \mathrm{O}$ background levels. The ${ }^{16} \mathrm{O}^{+}$signal is lower in the oxide layer when plasma cleaning is applied, except in the first nanometres of the oxide layer where the ${ }^{16} \mathrm{O}^{+}$profile shows a small hump (see Fig. 9(b)). This feature is also evident in the $\mathrm{H}^{+}$ profile, which suggests that the cleaning treatment removes adsorbed water and, thus, more clearly reveals hydrated alumina at the very outer surface of the aluminium oxide layer. Fig. 10 displays the ${ }^{11} \mathrm{~B}^{+}$and ${ }^{52} \mathrm{Cr}^{+}$profiles for the specimens with and without cleaning. The ${ }^{11} \mathrm{~B}^{+}$profile is not affected significantly by the cleaning process. The chromium delta layer appears slightly sharper in the profile obtained with application of cleaning. In addition, the background level, mainly caused by the ${ }^{40} \mathrm{Ar}^{12} \mathrm{C}^{+}$ interference, is reduced upon cleaning since it removes residual hydrocarbons prior to depth profiling.

\section{Simulation}

This possibility offered by the RF GD source configuration to generate a plasma for cleaning without sputtering material is new, and can be confirmed by calculation of the energies of the particles striking the surface of the specimen in the sheath near the specimen surface.

There is a good agreement between measured and calculated dc bias voltages that are 130 and $137 \mathrm{~V}$, respectively. The calculated plasma density is $10^{12} \mathrm{~cm}^{-3}$ and the maximum potential and electric field on the specimen are $-307 \mathrm{~V}$ and $10 \mathrm{kV}$ $\mathrm{cm}^{-1}$ respectively. The maximum time-varying sheath length is $0.6 \mathrm{~mm}$.

The potential and ionisation source term distributions are required as input parameters for the ion Monte Carlo model to

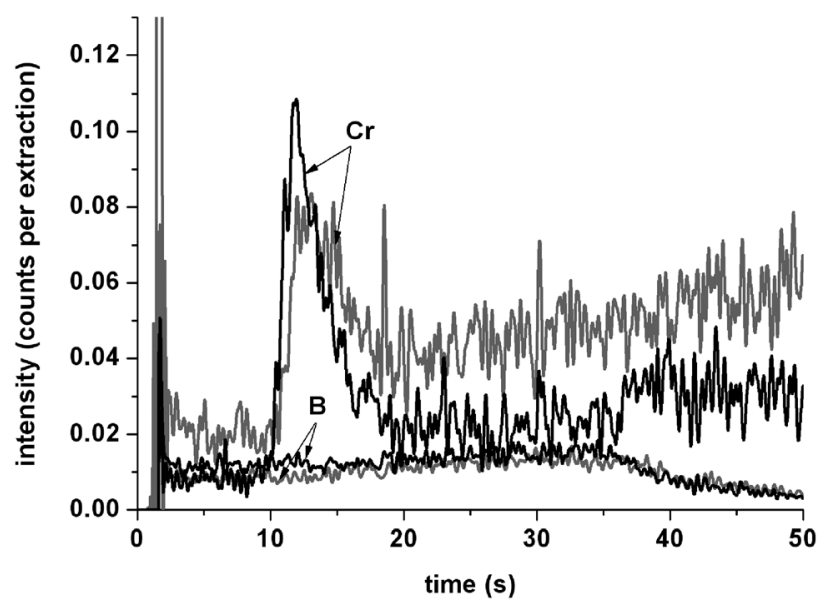

Fig. 10 Comparison of GD TOFMS $\mathrm{Cr}^{+}$and $\mathrm{B}^{+}$depth profiles of anodised aluminium sputtered at $650 \mathrm{~Pa}$ and $40 \mathrm{~W}$ with (black lines) and without (grey lines) plasma cleaning. The plasma cleaning conditions were $650 \mathrm{~Pa}$ Ar pressure and $2 \mathrm{~W}$ RF power applied for $2 \mathrm{~min}$. 


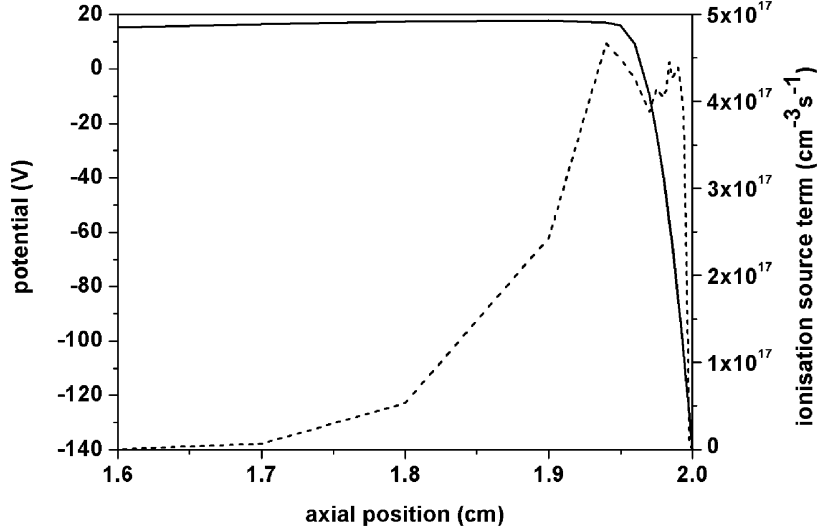

Fig. 11 Axial distribution of the mean potential (solid line) and ionisation source term (dash line). The sheath length is about $0.6 \mathrm{~mm}$.

calculate the ion energy distribution functions. At $13.56 \mathrm{MHz}$, ions are not able to follow the time varying potential, but they respond to the mean potential. In the present case, the mean potential corresponds to the dc bias of $-137 \mathrm{~V}$. The maximum energy of the ions is $137 \mathrm{eV}$, if the sheath is not collisional. The mean free path for the ions can be expressed as $1 / N \sigma$, where $N$ is
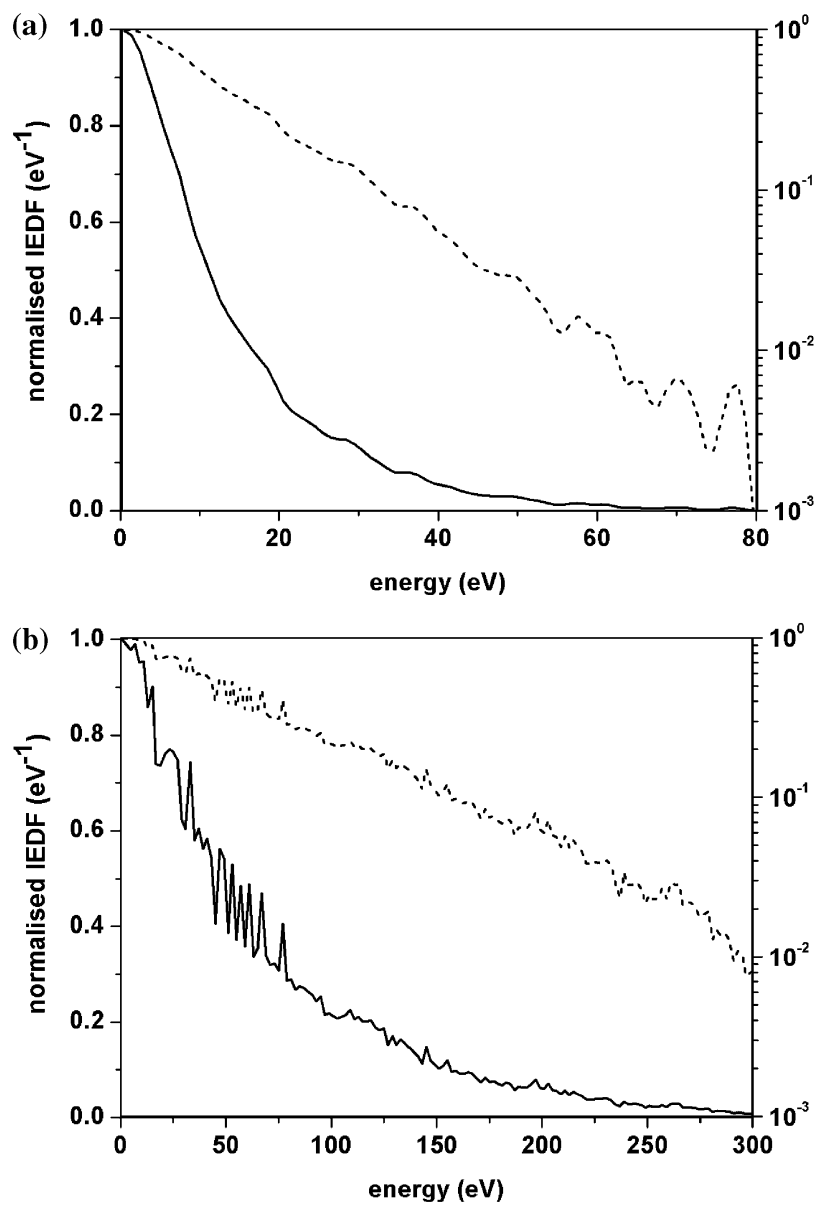

Fig. 12 Normalised ion energy distribution function plotted in linear scale (solid line) and logarithmic scale (dash line) calculated for: (a) cleaning conditions at pressure $400 \mathrm{~Pa}, V_{\mathrm{rf}}=-170 \mathrm{~V}, V_{\mathrm{dc}}=-137 \mathrm{~V}$ and (b) sputtering conditions at pressure $866 \mathrm{~Pa}, V_{\mathrm{rf}}=-350 \mathrm{~V}, V_{\mathrm{dc}}=-313 \mathrm{~V}$. the gas density and $\sigma$ is the collision cross section. The maximum cross section is about $5 \times 10^{-15} \mathrm{~cm}^{2}$, and the gas density is $9.63 \times$ $10^{16} \mathrm{~cm}^{-3}$ at $400 \mathrm{~Pa}$ and $300 \mathrm{~K}$. The mean free path for the ions is about $2 \times 10^{-3} \mathrm{~cm}$, indicating that the sheath is highly collisional.

Fig. 11 shows the axial mean potential and ionisation source term distribution used to calculate the ion energy distribution function. The calculated ion energy distribution function at cathode surface, displayed on linear and logarithmic scales, is shown in Fig. 12. The ion energy distribution function for precleaning conditions (Fig. 12(a)) reveals that ions can not reach high energies (about $300 \mathrm{eV}$ available in the sheath) because of charge exchange collisions. About $90 \%$ of the ions have energies below $30 \mathrm{eV}$, and most ions are thus unlikely to sputter material. The sputtering energy threshold ranges roughly from 15 to $50 \mathrm{eV}$, but few experiments are available to confirm these values for different materials and gases. The use of higher power and pressure as input parameter for the simulation shows that, under typical sputtering conditions, a significant number of ions hits the cathode surface with energies above the sputter threshold (Fig. 12(b)). The voltage drop across the "anode" sheath at the larger electrode is too low for the generation of the fast particles bombarding the anode wall. The voltage drop is only $33 \mathrm{~V}$ for the plasma cleaning conditions at $V_{\mathrm{rf}}=-170, V_{\mathrm{dc}}=-137 \mathrm{~V}$.

Other mechanisms therefore contribute to the plasma cleaning effect observed. Low energy ions may contribute to cleaning by fragmenting and desorbing organic molecules that are physisorbed or chemisorbed on the surface. In addition to a dissociative charge transfer process, ${ }^{22}$ metastable species formed from low energy particles (ions and neutrals) can also induce contaminant desorption as seen in direct analysis in real time (DART) experiments. ${ }^{23}$

\section{Conclusions}

Plasma cleaning is a useful method for improving the quality of elemental depth profiling in glow discharge spectrometry. In this study, plasma cleaning was applied to electropolished aluminium and electropolished aluminium supporting an anodic film as target materials. Platinum layers on silicon and polymer were also used to assess the possible damage of the surface caused by plasma cleaning. The application of plasma cleaning prior to depth profiling effectively removes contaminants from both the specimen surface and the inner surfaces of the anode, resulting in enhancement of the plasma stability at the commencement of sputtering. Stabilisation of the plasma, together with removal of contaminants, greatly reduces the usual distortion of the profiles evident at the commencement of sputtering, e.g. long tails of hydrogen and carbon profiles in GD OES. Additionally, in GD TOFMS, long tails, associated with the presence of water molecules and carbon, are effectively reduced by plasma cleaning. Importantly, the plasma cleaning conditions, e.g. power and duration, should be carefully adjusted with respect to the main matrix component of the material to avoid damage.

The concept of the proposed plasma cleaning includes two approaches. The first and innovative approach is based on the application of low energy plasma, e.g. "soft" plasma, that mainly removes contaminants from the surface of the target material. In the second approach, classically applied by the GD community, the sputtering of sacrificial material, e.g. monocrystalline silicon, 
is undertaken under conditions similar to those used for depth profiling. The conditions of soft plasma cleaning need to be optimised to prevent material damage.

The two approaches can be performed in a single sequence with a sacrificial specimen first sputtered to clean the anode, followed by soft cleaning of the specimen surface prior to analysis.

The calculated ion energy distribution function under plasma cleaning discharge conditions shows that most of the ions striking the surface are low energy ions; this supports the experimental evidence that the specimen is not damaged by the soft plasma.

\section{Acknowledgements}

This work was supported by FP6 Contract STREP-NMP, $\mathrm{N}^{\circ}$ 032202. Ph. Belenguer would like to thank L. C. Pitchford for providing the Monte Carlo code for the ions and numerous useful discussions.

\section{References}

1 Th. Nelis and R. A. Payling. Guidebook to Glow Discharge Optical Emission Spectroscopy, RSC Publishing, Cambridge, UK, 2004; K. Shimizu, H. Habazaki, P. Skeldon and G. Thompson, Surf. Interface Anal., 2003, 35, 564-574.

2 N. E. Sanderson, E. Hall, J. Clark, P. Charalambous and D. Hall, Mikrochim. Acta, 1987, 1, 275-290.

3 M. Kasik, C. Michellon and L. C. Pitchford, J. Anal. At. Spectrom., 2002, 17, 1398-1399; M. Hohl, A. Kanzari, J. Michler, T. Nelis, K. Fuhrer and M. Gonin, Surf. Interface Anal., 2006, 38, 292-295; A. C. Muñiz, J. Pisonero, L. Lobo, C. Gonzalez, N. Bordel, R. Pereiro, A. Tempez, P. Chapon, N. Tuccitto, A. Licciardello and A. Sanz-Medel, J. Anal. At. Spectrom., 2008, 23, 1239-1246.

4 N. Tuccitto, L. Lobo, A. Tempez, I. Delfanti, P. Chapon, S. Canulescu, N. Bordel, J. Michler and A. Licciardello, Rapid Commun. Mass Spectrom., 2009, 23, 549-556.

5 K. Shimizu, R. Payling, H. Habazaki, P. Skeldon and G. E. Thompson, J. Anal. At. Spectrom., 2004, 19, 692-695.

6 D. Klemm, M. Stangl, A. Peeva, V. Hoffmann, K. Wetzig and J. Eckert, Surf. Interface Anal., 2008, 40, 418-422; M. Aeberhard,
T. Nelis, J. Michler and E. Barisone, Poster Presentation at Fourth International Glow Discharge Day, Longjumeau, France, 29th September 2008.

7 R. Payling, J. Michler and M. Aeberhard, Surf. Interface Anal., 2002, 33, 472-477.

8 ISO 18116:2005(E) Surface chemical analysis - Guide to preparation and mounting of specimens for analysis.

9 D. Klemm, M. Stangl, A. Peeva, V. Hoffmann, K. Wetziga and J. Eckert, Surf. Interface Anal., 2008, 40, 418-422.

10 E. W. McDaniel, Collision phenomena in ionized gases, John Wiley \& Sons, New York, 1964.

11 V. S. Smentkowski, Prog. Surf. Sci., 2000, 64, 1-58.

12 P. Sigmund, Phys. Rev., 1969, 184, 383-416.

13 C. Pédoussat, Thèse d'Université, Université Paul Sabatier, 1999; C. Macé, Thèse d'Université, Université Paris Sud, 2001.

14 Y. Yamamura and K. Tawara, At. Data Nucl. Data Tables, 1996, 62, 149-253.

15 K. Shimizu, G. M. Brown, H. Habazaki, K. Kobayashi, P. Skeldon, G. E. Thompson and G. C. Wood, Corros. Sci., 1999, 41, 19711976.

16 M. Ganciu, S. Konstantinidis, Y. Paint, J. P. Dauchot, M. Hecq, L. de Poucques, P. Vašina, M. Meško, J. C. Imbert, J. Bretagne, M. Touzeau and J. Optoelectron, Adv. Mater., 2005, 7, 2481-2484; P. Vasina, M. Mesko, M. Ganciu, J. Bretagne, C. Boisse-Laporte, L. de Poucquesa and M. Touzeau, Europhys. Lett., 2005, 72, 390395; S. Konstantinidis, J. P. Dauchot, M. Ganciu, A. Ricard and M. Hecq, J. Appl. Phys., 2006, 99, 013307.

17 M. Hohl, A. Kanzari, J. Michler, T. Nelis, K. Fuhrer and M. Gonin, Surf. Interface Anal., 2006, 38, 292-295; A. C. Muñiz, J. Pisonero, L. Lobo, C. Gonzalez, N. Bordel, R. Pereiro, A. Tempez, P. Chapon, N. Tuccitto, A. Licciardello and A. Sanz-Medel, J. Anal. At. Spectrom., 2008, 23, 1239-1246.

18 A. Fiala, L. C. Pitchford and J. P. Bœuf, Phys. Rev. E, 1994, 49, 5607 5622; Ph. Belenguer, L. C. Pitchford and J. C. Hubinois, J. Anal. At. Spectrom., 2001, 16, 1-3.

19 A. V. Phelps, C. H. Greene and J. P. Burke Jr., J. Phys. B, 2000, 33, 2965-2981.

20 P. Skeldon, X. Zhou, G. E. Thompson, G. C. Wood, H. Habazaki and K. Shimizu, Thin Solid Films, 1997, 293, 327-332.

21 A. Bengtson, J. Anal. At. Spectrom., 2003, 18, 1066-1068.

22 T. L. Williams, L. M. Babcock and N. G. Adams, Int. J. Mass Spectrom., 1999, 185/186/187, 759-772.

23 D. Ochs, J. Schroeder, B. Cord and J. Scherer, Surf. Coat. Technol., 2001, 142-144, 767-770; P. B. Armentrout, J. Anal. At. Spectrom., 2004, 19, 571-580; R. B. Cody, J. A. Larame and H. D. Durst, Anal. Chem., 2005, 77, 2297-2302. 